\title{
O papel do cirurgião nas valvopatias reumáticas tratadas com valvoplastia percutânea
}

\author{
Antoninho S. ARNONI*, Pedro R. SALERNO*, A. T. M. HENRIQUES NETO* Jarbas J. DKINKHUYSEN*, \\ Paulo CHACCUR*, Camilo ABDULMASSIH NETO*, S. L. NAVARRO*, C. A. ESTEVES*, A. I. O. RAMOS*, \\ J. Eduardo M. R. SOUSA*, Adib D. JATENE*, Luiz Carlos Bento de SOUZA*, Paulo P. PAULISTA*
}

RBCCV 44205-77

\begin{abstract}
ARNONI, A. S.; SALERNO, P. R.; HENRIQUES NETO, A. T. M.; DINKHUYSEN, J. J.; CHACCUR, P.: ABDULMASSIH NETO, C.; NAVARRO, S. L.; ESTEVES, C. A.; RAMOS A. I. O.; SOUSA, J. E. M. R.; JATENE, A. D.; SOUZA, L. C. B.; PAULISTA, P.P. - O papel do cirurgião nas valvopatias reumáticas tratadas com valvoplastia percutânea. Rev. Bras. Cir. Cardiovasc., 4(1): 51-63, 1989.

RESUMO: No Instituto Dante Pazzanese de Cardiologia, as valvoplastias percutâneas para as valvas mitral e aórtica tiveram início em agosto de 1987. Foram realizados 37 procedimentos, sendo 26 para a mitral (VMP) e 1 para a aórtica (VAP). Nas 26 VMP, obteve-se sucesso 14 vezes, tendo 4 complicações. Em 3 pacientes, o sucesso não foi total, sendo que uma paciente com insuficiência mitral recusou cirurgia, outro foi operado e o terceiro está assintomático, mas não houve melhora da área valvar e das pressōes, e deve ser reestudado para posterior avaliaçăo. Os 9 pacientes restantes foram operados, sendo realizadas 6 comissurotomias e papilarotomias e 3 substituições valvares. A indicação cirúrgica se deu por tamponamento cardiaco em 1 caso, rotura de músculo papilar com conseqüente insuficiência em outro, 1 caso de baixo débito, punção da aorta em 4 casos e nâo passagem do cateter para o átrio esquerdo em 2 com suspeita de tamponamento não confirmada. O paciente submetido a VAP obteve melhora imediata do gradiente, mas faleceu 1 mês após, em insuficiência cardíaca. As valvoplastias percutâneas têm apresentado uma alternativa no tratamento das lesōes valvares e são uma opçâo, principalmente para casos de valvas não calcificadas e com o aparelho subvalvar não comprometido. Devem ser lembradas nos casos em que a cirurgia é de alto risco, como em idosos, pneumopatas e nefropatas.
\end{abstract}

DESCRITORES: valvoplastia percutânea, cirurgia; valvas cardiacas, cirurgia

\section{INTRODUÇĀO}

A terapêutica cirúrgica para correção de valvas cardiacas estenóticas tem sofrido modificaçōes e evoluçōes desde o início da cirurgia cardíaca. A valva mitral, a princípio, foi tratada com técnicas a "céu fechado", através de comissurotomias digitais, ou emprego de valvulótomos. Desde 1920, CUTLER \& BECK ${ }^{13}$, BAILEY $^{4}$ e HARKEN et alii ${ }^{18}$ apresentarain várias técnicas, sugerindo que a fusão das cornissuras pudesse ser tratada mecanicamente. Essas técnicas tinham sua indicação em casos selecionados e as complicaçōes e reestenoses tardias foram descritas. Com a circulação extracorpórea e a realização de cirurgia sob visão direta, possibilitando a análise e o tratamento da valva, os resultados melhoraram, tanto precoce, como tardiamente.

Já com relação à valva aórtica, as experiências com comissurotomia "fechada", ou sob visão direta, empregando-se valvulótomos ${ }^{25}$, mostravam resultados pouco animadores e nenhuma, ou pequena, melhora clínica a longo prazo. A evolução das técnicas de extracorpórea 
ARNONI, A. S.; SALERNO, P. R.; HENRIQUES NETO, A. T. M.; DINKHUYSEN, J. J.; CHACCUR, P.; ABDULMASSIH NETO, C.; NAVARRO, S. L.; ESTEVES, C. A.; RAMOS, A. I. O.; SOUSA, J. E. M. R.; JATENE, A. D.; SOUZA, L. C. B.; PAULISTA, P. P. - O papel do cirurgiāo nas valvopatias reumáticas tratadas com valvoplastia percutânea. Rev. Bras. Cir. Cardiovasc., 4(1): 51-63, 1989.

e a abordagem direta das valvas, permitindo descalcificações e abertura das comissuras, fez com que esses resultados melhorassem e que, hoje, possam ser realizados com risco bastante aceitável.

Mas a morbidade e a mortalidade dos procedimentos cirúrgicos estão na dependência de vários fatores, tais como condições gerais, cardiológicas e idade dos pacientes. Baseados nisso, nas experiências anteriores com dilatações cirúrgicas e apoiados na crescente evolução das técnicas de angioplastia transluminal coronária, alguns autores procuraram desenvolver cateteres para realização de dilatações de valvas estenóticas, nos laboratórios de hemodinâmica.

A primeira valvoplastia mitral percútânea (VMP) com cateter-balão bem sucedida foi realizada por INDUE et alii $^{22}$, em 1984, utilizando a técnica com um único balāo. Logo após, LOCK et alii ${ }^{28}$, em 1985, descreveram seus resultados em 8 crianças e adolescentes. Em 1986, AL ZAGAIB et alii ${ }^{1}$ introduziram a técnica de 2 balões na dilatação da valva mitral. Todos esses procedimentos foram efetuados em jovens sem evidências de calcificação e usando-se a técnica transeptal. McKAY ${ }^{30}$ e PALACIOS et alii ${ }^{36}$ ampliaram a indicação para adultos. BABIC et alii $^{3}$ introduziram a técnica de valvoplastia retrógrada, com o cateter vindo pela aorta e abordando a mitral pelo lado ventricular.

Já com relação à valva aórtica, as primeiras valvoplastias aórticas percutâneas (VAP) foras realizadas por LABABIDI \& WEINHAUS ${ }^{24}$, em 1984, em crianças e adolescentes. Seus resultados foram corroborados por RUPRATH \& NEUHAUS ${ }^{43}$, em 3 crianças com 4 semanas de idade. Em 1986, CRIBIER et alii ${ }^{11}$ descrevem dilatação de valva aórtica calcificada. Seguem-se, logo após, vários trabalhos, como os de McKAY et alii ${ }^{32}$ e de CRIBIER et $a i_{i j}{ }^{12}$. Algumas modificaçōes foram realizadas, como as técnicas anterógradas via transeptal e a dissecçāo das artérias femorais, visando evitar danos provocados pela punção e/ou emprego de duplo balão descrito por DORROS et alii ${ }^{14}$

Todos os procedimentos de valvoplastias necessitam do suporte da equipe cirúrgica, uma vez que existe a possibilidade de complicaçōes que requerem o cirurgião para sua correçāo.

A finalidade deste trabalho é mostrar qual o papel desempenhado pela equipe de cirurgia, nas dilatações com cateter-balão, quer tratando as complicaçōes passíveis de correção, quer realizando comissurotomias ou substituiçōes valvares, nos casos de insucesso a curto e longo prazo.

\section{CASUISTICA E MÉTODOS}

No Instituto Dante Pazzanese de Cardiologia, desde agosto e 1987, 27 pacientes foram submetidos a valvo- plastia percutânea, sendo 26 para a valva mitral e 1 para a aórtica.

A técnica empregada para a valvoplastia mitral foi a transeptal. Pela veia femoral, atinge-se o septo interatrial, que é dilatado com o auxilio de um pequeno balão. Pelo orifício formado, passam-se dois cateteres-balão, com diâmetros previamente selecionados para o caso, conduzindo-os até o plano da valva mitral. A insuflação dos balōes é simultânea, utilizando-se soro-contraste $(50 \%)$ até que a imagem em ampulheta formada pela valva estenótica seja desfeita. Terminado o procedimento, são feitas medidas pressóricas de ventrículo esquerdo e átrio esquerdo para determinação do gradiente transvalvar. Em seguida, faz-se injeção do contraste em átrio esquerdo e ventrículo esquerdo, para análise do esvaziamento do átrio e da presença, ou nāo, de refluxo valvar. O suceso é obtido quando há diminuição do gradiente sem a presença de insuficiência.

Para a valvoplastia aórtica, a técnica empregada foi a transarterial. Pela artéria femoral e sob fluoroscopia direta, progride-se um cateter de furo terminal empregado para medida pressórica. Por esse cateter, introduz-se um fio guia. Retira-se o cateter e, sobre o fio guia, introduz-se um cateter-balão, que é posicionado no plano valvar e inflado com soro-contraste $(50 \%)$. Terminada a dilatação, realizam-se medidas pressóricas no ventrículo esquerdo e na aorta, considerando-se sucesso quando o gradiente agora obtido é pelo menos $50 \%$ menor que $o$ inicialmente registrado.

Para que o procedimento seja efetuado, os pacientes são submetios a exames pré-operatórios, tipagem e reserva de sangue. A equipe cirúrgica fica de prontidão informal, ou seja, o programa cirúrgico transcorre normalmente, mantendo-se uma sala operatório preparada para qualquer eventualidade.

\section{RESULTADOS}

Nos 26 pacientes submetidos a VMP, obteve-se sucesso em 14 ocasiōes, 4 das quais tiveram complicações. Uma paciente apresentou distúrbio de comportamento temporário; outra teve parada cardíaca, recuperada sem seqüelas; uma terceira apresentou sangramento excessivo no local da punção e AVC à esquerda, 2 dias depois, e o último, com quadro de abdome agudo, necessitou exploração cirúrgica que demonstrou hematoma retroperitoneal. Os 14 pacientes permanecem assintomáticos, em evolução média de 7,8 meses ( 2 a 17 meses). Todos estão em grupo funcional I e apenas 1 paciente, que apresentou AVC como complicação, permanece com déficit motor.

Em 3 vezes, não se obteve sucesso total; um dos pacientes, que apresentava discreta insuficiência mitral, aumentou o refluxo, mas recusou ser operado, encon- 
ARNONI, A. S.; SALERNO, P. R.; HENRIQUES NETO, A. T. M.; DINKHUYSEN, J. J.; CHACCUR, P.; ABDULMASSIH NETO, C.; NAVARRO, S. L.; ESTEVES, C. A.; RAMOS, A. I. O.; SOUSA, J. E. M. R.; JATENE, A. D.; SOUZA, L. C. B.; PAULISTA, P. P. - O papel do cirurgiāo nas valvopatias reumáticas tratadas com valvoplastia percutânea. Rev. Bras. Cir. Cardiovasc., 4(1): 51-63, 1989.

trando-se em grupo funcional III. Trata-se de paciente com 72 anos, portador de doença obstrutiva pulmonar crônica associada e com alto risco cirúrgico. Em outro, nâo houve queda das pressōes durante a valvoplastia, mas o paciente está em evolução há 4 meses e permanece assintomático. Deve ser reestudado, para posterior avaliação. O último teve AVC transitório e foi acompanhado por 3 meses e, como nos exames clínicos e ecocardiográficos nāo mostrassem melhora (área valvar 1,3 $\mathrm{cm}^{2}$ ), foi encaminhado à cirurgia, onde se realizaram comissurotomia, descalcificação da cúspide anterior e papilarotomia. Está com 2 meses de pós-operatório, assintomático.

Os restantes 9 pacientes foram encaminhados à cirurgia durante a fase hospitalar. Sete foram operados no mesmo dia (4 de imediato e 3 com 2 horas após a VMP), um com 2 dias e outro com 1 semana. Dos que foram levados imediatamente à sala cirúrgica, 1 apresentava tamponamento, drenado na sala de hemodinâmica e, no ato operatório, constatou-se perfuraçāo do átrio direito junto à veia cava superior e do ventrículo direito, necessitando correçāo, Em 2 casos, a aorta foi puncionada com a agulha de Brockenburg, utilizada para perfurar o septo interatrial, e na cirurgia, 1 tinha 300 $\mathrm{ml}$ de sangue na cavidade pericárdica e outro, um hematoma na face lateral esquerda da aorta, sem sangue no pericárdio. $O$ último paciente foi diretamente da sala de hemodinâmica para cirurgia, por apresentar quadro de baixo débito.

Dos 3 pacientes operados com 2 horas pós VMP, em 2 houve punção da aorta, sendo que, em 1 dos casos, havia $200 \mathrm{ml}$ de sangue no pericárdio. No terceiro, nāo se conseguiu perfurar o septo e foi à sala operatória com suspeita de tamponamento, nāo confirmado.

Um paciente apresentou insuficiência mitral severa e os estudos com ecocardiografia mostraram rotura de músculo papilar. Foi operado 2 dias depois, com confirmação da lesão que obrigou a substituição valvar.

A paciente operada uma semana depois era portadora de insuficiência renal crônica e na qual não se conseguiu passar o septo. Após melhora das condiçōes gerais da paciente, ela foi conduzida à sala cirúrgica.

Com relação à cirurgia, em 6 ocasiōes realizaram-se comissurotomia e papilarotomia bilateral e, em 3 , substituição valvar. Todos os 6 pacientes submetidos a comissurotomia apresentavam importante fusão dos músculos papilares, que comprometiam a dinâmica das valvas. Necessitaram de ampla panilarotomia para que a abertura ficasse satisfatória. Ém 2 deles, havia calcificação, que precisou ser removida.

As substituiçōes valvares foram feitas por impossibilidade de conservar o aparelho valvar, uma das vezes, na paciente que teve rotura de músculo papilar. Nos outros 2 casos, as valvas tinham cúspides intensamente calcificadas, sem mobilidade e com o aparelho subvalvar comprometido. Nas 3 ocasiōes, foram empregadas próteses biológicas. Uma das pacientes, além da mitral, teve tratada a valva aórtica, que apresentava calcificação e estenose das válvulas, necessitando descalcificação e comissurotomia. Esta paciente apresentou quadro de coagulopatia e baixo débito, sendo, inclusive, reoperada para revisão de hemostasia e vindo a óbito com 6 dias de pós-operatório.

Em 2 oportunidades, tivemos que intervir cirurgicamente nas artérias femorais que apresentavam sangramento excessivo.

O paciente aórtico apresentou melhora imediata com aumento da área valvar. Retornou uma semana depois, com aumento da sintomatologia, vindo a óbito 1 mês depois. Tratava-se de paciente com função ventricular bastante comprometida e com alto risco cirúrgico.

\section{DISCUSSĀO}

Nos últimos anos, os laboratórios de hemodinâmica deixaram de ser apenas diagnósticos e passaram, também, a ser terapêuticos. Assim é que algumas cardiopatias congênitas são tratadas com balão de Rashkind, com aortoplastias ou com valvoplastias; as obstruções coronárias são manuseadas com angioplastia transluminal coronária e, mais recentemente, as valvas mitral e aórtica são dilatadas por cateter-balão.

Em todos estes procedimentos, a equipe cirúrgica deve ficar de prontidāo e os pacientes devem estar preparados para uma eventual cirurgia, com exames pré-operatórios e com tipagem, além de reserva de sangue nos bancos de sangue. Vários tipos de prontidão são descritos pela literatura e são observados pelas diferentes equipes cirúrgicas ${ }^{34}$. O mais rígido é aquele chamado de "formal", no qual a sala cirúrgica fica preparada e o cirurgião acompanha o exame na sala de hemodinâmica. Um pouco mais maleável é o "informal", no qual a equipe cirúrgica mantém uma sala preparada, mas vai seguindo sua programação normal. Este é o modo como temos ficada de prontidão. Existem, ainda, grupos em que a prontidão é mais informal, ou seja, a equipe cirúrgica sabe da realização de procedimento, mas não deixa sala preparada e coloca o paciente na primeira sala que for desocupada. O que não se admite, hoje, é que a equipe cirúrgica siquer saiba da realização das dilataçōes e que só depois da ocorrência de qualquer complicação é comunicada e passe a tomar providências. Quase sempre, o tempo entre as complicações e sua correção é um fator decisivo no resultado.

Várias são as questōes que podem ser formuladas a respeito das dilataçōes valvares mitral e aórtica. As 
ARNONI, A. S.; SALERNO, P. R.; HENRIQUES NETO, A. T. M.; DINKHUYSEN, J. J.; CHACCUR, P.; ABDULMASSIH NETO, C.; NAVARRO, S. L.; ESTEVES, C. A.; RAMOS, A. I. O.; SOUSA, J. E. M. R.; JATENE, A. D.; SOUZA, L. C. B.; PAULISTA, P. P. - O papel do cirurgiāo nas valvopatias reumáticas tratadas com valvoplastia percutânea. Rev. Bras. Cir. Cardiovasc., 4(1): 51-63, 1989.

cirurgias sob visão direta, para estas duas valvas, são realizadas há muitos anos, com resultados bastante satisfatórios a curto e longo prazo, o que nos faz levantar algumas dúvidas, quais sejam as indicaçōes, o que é considerado sucesso, o número e os tipos de complicaçōes e os resultados imediato e tardio das VMP e VAP.

As indicaçōes têm-se modificado com a evolução das técnicas. Começaram a ser utilizadas apenas em crianças e adolescentes e foram ampliadas para adultos. A característica da valva a ser tratada também tem sido variada $^{45}$.

BROCK ${ }^{6}$ define como bons candidatos a VMP aqueles com boa mobilidade valvar, nenhum cálcio, mínimo espessamento das cúspides e nenhuma alteração subvalvar. Deverão ser jovens e apresentar ritmo sinusal. Seriam maus candidatos os com valva calcificada, rígida, com fibrose valvar e subvalvar. Estas características da valva, associadas à idade avançada e ao longo tempo de fibrilação atrial, piorariam o prognóstico. Parece não ter efeito sobre o resultado a associação de discretas alteraçōes em outras valvas, uma regurgitaçāo mitral discreta, disfunção do ventrículo esquerdo, comissurotomias prévias e pequenas calcificaçōes; seriam contraindicaçōes a associação de outra valvopatia com indicação cirúrgica, a associação com cirurgia de coronária, a presença de trombo em átrio esquerdo, o espessamento do septo atrial, grande calcificaçāo valvar, a presença de trombo em ventrículo esquerdo e episódios de tromboembolismo.

PALACIOS et alii ${ }^{36}$ concordam com o fato de que esses pacientes com trombo em átrio esquerdo visivel ao ecocardiograma devam ser excluidos, mas realizam o método nos casos com fibrilação atrial. Não encontraram correlação entre os seus resultados e a idade, comissurotomias prévias e, mesmo, com calcificação discreta ou moderada da valva. Fazem a ressalva, entretanto, de que o processo reumático deforma a valva e que, em casos avançados, a fibrose pode encurtar, fusionar e imobilizar as cúspides, as cordas tendineas e os músculos papilares, formando um rígido funil. Nesses casos, a valvoplastia não teria bom resultado.

HERMANN et alii ${ }^{20}$ dão, como sinais de um resultado sub-ótimo, um alto escore ecocardiográfico, a fibrilaçăo atrial e um pequeno quociente entre a área valvar e a superfície corporal. O escore ecocardiográfico leva em consideraçăo 4 fatores, quais sejam: a mobilidade da cúspide, o espessamento da cúspide, o espessamento subvalvar e a calcificação. Atribui-se pontuação de 0 a 4 do normal ao máximo de alteração. Assim, contagens abaixo de 8 seriam de bom prognóstico e acima de 11, de mal prognóstico, tanto a curto, como a longo prazo. É evidente que a análise de cada um dos fatores, por si só, deve ser considerada, uma vez que 2 valvas podem ter a mesma pontuação por motivos diferentes e, se uma delas tiver o máximo de calcificação, será pior que a outra.

McKAY ${ }^{30}$ considera, como candidatos a VMP, os pacientes de alto risco para cirurgia, por hipertensão pulmonar severa, insuficiência cardíaca, ou associação de outras condições anormais, como doenças pulmonares e renais. Seriam também candidatos, na sua opinião, os pacientes que não podem usar anticoagulantes, ou que têm contra-indicaçōes para prótese biológica.

Outra indicaçāo que tem sido preconizada para a VMP é para pacientes grávidas. A cirurgia cardiaca, na grávida, tem apresentado bom desenvolvimento e bom controle, tanto da mãe como do feto, mas ainda apresenta perda fetal em alguns casos, dependendo de vários fatores, tais como a idade gestacional e as condiçōes maternas ${ }^{2}$.

SAFIAN et alii ${ }^{44}$, descrevem a realização de VMP em grávida de 39 anos, no primeiro trimestre de gravidez. A exposição do feto à radiação foi pequena, segundo seus cálculos, e a gravidez veio a termo com bom resultado. PALACIOS et alii ${ }^{37}$ relatam também VMP em paciente de 41 anos, com 21 semanas de gestação, na qual obtiveram sucesso, com o restante da gravidez e o nascimento da criança transcorrendo sem complicaçōes.

Com relaçāo à valvoplastia aórtica, ela tem sido indicada principalmente para pacientes com idade superior a 70 anos, ou para aqueles em que o risco cirúrgico é muito grande. Recentemente, alguns autores ${ }^{26}$ advogam sua aplicação para mulheres em idade fértil, ou para pacientes com estenose moderada, sem indicação cirúrgica, mas que apresentavam melhora dos sintomas com a dilatação.

Outros ${ }^{24}$ acreditam que possa ser usada em neonatos, pelo menos para retardar a necessidade de cirurgia, até uma idade em que a mortalidade seja menor.

A insuficiência aórtica limitaria o processo. A calcificaçāo da valva não é impedimento para que a dilatação seja tentada. McKAY ${ }^{30}$ considera candidatos os de alto risco que sāo recusados pela cirurgia devido à idade avançada, doença renal e doença pulmonar crônica. McKAY et alii ${ }^{31}$ indicam VAP para portadores de coronariopatia cirúrgica associada, realizando os 2 procedimentos, mas apenas em pacientes de alto risco, ou que recusam cirurgia.

VANDORMAEL et alii ${ }^{46}$ acreditam que a estenose aórtica e a obstrução coronária possam ser tratadas por dilatação. Descreve caso em que dilatou primeiro a valva aórtica e, 2 semanas depois, realizou angioplastia para artéria circunflexa.

HAMAD et alii ${ }^{16}$ descrevem 2 casos em que a VAP foi acompanhada de angioplastia. Um dos pacientes vol- 
ARNONI, A. S.; SALERNO, P. R.; HENRIQUES NETO, A. T. M.; DINKHUYSEN, J. J.; CHACCUR, P.; ABDULMASSIH NETO, C.; NAVARRO, S. L.; ESTEVES, C. A.; RAMOS, A. I. O.; SOUSA, J. E. M. R.; JATENE, A. D.; SOUZA, L. C. B.; PAULISTA, P. P. - O papel do cirurgião nas valvopatias reumáticas tratadas com valvoplastia percutânea. Rev. Bras. Cir. Cardiovasc., 4(1): 51-63, 1989

tou 1 mês depois, com reestenose tanto na valva como nas coronárias e, como era de alto risco cirúrgico, fol tentada nova valvoplastia, mas faleceu 36 horas depois. O segundo paciente, com 88 anos de idade, evoluiu bem.

Uma vez indicada a valvoplastia, deve-se escolher a técnica de abordagem das valvas. Para a mitral, podese usar a técnica transeptal, como descrito por INOUE et alii ${ }^{22}$, realizadores do primeiro procedimento bem sucedido. Outra possibilidade é a técnica retrógrada, abordando a valva pela face ventricular, como descreveram BABIC et alii ${ }^{3}$. Cada uma das técnicas apresenta vantagens e desvantagens, que devem ser analisadas quando de seu emprego.

Para a valva aórtica, também há duas possibilidades, ou sejam, a transarterial, chegando-se à valva pela aorta, como descreveram LABABIDI \& WEINHAUS ${ }^{24}$,ou a anterógrada, perfurando o septo, como descreveram PALACIOS \& BLOCK ${ }^{35}$

Em nosso Serviço, dá-se preferência à técnica transeptal para as VMP e a técnica transarterial para as VAP.

Ainda com relação à técnica, podemos dizer que, a princípio, usava-se um só balão e que, atualmente, prefere-se o emprego de duplo balāo, com dimensōes determinadas pelo diâmetro valvar que se deseja obter. $O$ emprego de balōes de tamanho maior que 0 anel valvar pode acarretar complicaçōes. Atualmente, dispōe-se, para valvoplastias, de diferentes tipos de baIóes, como os descritos por MEIER et alii ${ }^{33}$ e que, por terem pequenos balốes em um só, são chamados trefoil.

O mecanismo pelo qual as dilatações ocorrem tem sido motivo de análises variadas.

RIBEIRO et alii ${ }^{39}$ estudaram valvas intactas, retiradas de pacientes submetidos a cirurgia, e descrevem que a abertura das comissuras é a maneira pela qual se faz a dilatação. Seu trabalho foi realizado com duplo balāo. Referem, ainda, que o estudo não considerou as estruturas subvalvares, que só foram preservadas em alguns casos. Acreditam que a textura da valva $e$ a análise do aparelho subvalvar sejam importates, apesar de referirem que, nos casos em que analisaram o aparelho subvalvar, o papel desempenhado por essa estrutura fosse pequeno. A abertura, segundo eles, concordando com KAPLAN et alii ${ }^{23}$, se faz mais na.comissura calcificada do que na sem cálcio. Em duas ocasiōes, durante a experiência, houve liberação de fragmentos de cálcio.

KAPLAN et alii ${ }^{23}$ realizaram estudos semelhantes, com emprego de 1 único balão, e relatam o mesmo mecanismo, com abertura das comissuras que são rasgadas pelo balão, dando um aumento funcional à valva, semelhante ao das comissurotomias cirúrgicas. Três li- mitações podem ser feitas a estes estudos, como relata o próprio Kaplan, ou seja: o aparelho subvalvar não é analisado: não se pode testar o grau de insuficiência e, evidentemente, não se analisam as reestenoses.

BLOCK et alii ${ }^{8}$ analisaram as valvas de 2 pacientes submetidos a valvoplastia, sendo 1 post-mortem e 1 na cirurgia. Dizem que há abertura das comussuras, mas que o aparelho subvalvar limita essa abertura e, assim, não há alivio de sintomas.

WILKINS et alii ${ }^{48}$, através de estudo ecocardiográfico, relatam que o sucesso das dilataçōes em mitral é associado a uma clivagem ao longo das comissuras, e ela ocorre mesmo em valvas calcificadas, ou espessadas, mas em grau menor. Nos casos em que há alto escore ecocardiográfico, mesmo com grande abertura das comissuras, a separação das cúspides na diástole é pobre.

A valva aórtica também tem sido estudada em necropsias, ou no intra-operatṕrio. ROCHA et alii ${ }^{41}$ relatam casos em que a calcificação em idosos, não é acompanhada de fusão comissural, e a valvoplastia provocaria fratura das calcificaçōes nodulares melhorando a flexibili-

Em nosso grupo, realizamos a dilatação intra-operatória da mitral em 3 ocasiōes. Em uma delas, a valva não servia para comissurotomia, pois era bastante calcificada. A colocaçāo dos balōes e sua insuflação nāo provocaram resultado algum. No segundo caso, a abertura conseguida foi pequena e necessitamos complementar com comissurotomia. Os papilares não foram afetados pela dilatação e foram separados cirurgicamente, conferindo boa abertura à valva. No terceiro caso, a abertura se deu fora das comissuras, e houve necessidade de substituição valvar.

dade das válvulas, podendo levar a melhor coaptação das mesmas, inclusive melhorando pequenas insuficiências.

McKAY et alii ${ }^{32}$, realizando estudos post-mortem, ou em pacientes na sala cirúrgica, acreditam que os mecanismos sejam variados, incluindo separação das comissuras fusionadas, fratura de calcificaçōes nodulares e deformidade das válvulas.

Realizamos a dilatação intra-operatória da valva aórtica em 1 paciente com estenose severa e intensa calcificação. Houve emprego de apenas um balẫo. Apesar do balão ser inflado totalmente, a valva, depois de retirado o balão, voltava à situação inicial. A nossa observação concorda com o que é descrito por COMMEAU et alii ${ }^{10}$ de que a dilatação não alteraria a mobilidade.

ROBICSEK \& HAROLD ${ }^{40}$, fazendo análise intra-operatória, descrevem que o balão força as válvulas na posição aberta, mas eles reaproximam, imediatamente após a deflação do balāo.

Mas uma questäo que sempre surge para métodos novos é a definiçāo de sucesso, e ele pode ser definido 
ARNONI, A. S.; SALERNO, P. R.; HENRIQUES NETO, A. T. M.; DINKHUYSEN, J. J.; CHACCUR, P.; ABDULMASSIH NETO, C.; NAVARRO, S. L.; ESTEVES, C. A.; RAMOS, A. I. O.; SOUSA, J. E. M. R.; JATENE, A. D.; SOUZA, L. C. B.; PAULISTA, P. P. - O papel do cirurgiāo nas valvopatias reumáticas tratadas com valvoplastia percutânea. Rev. Bras. Cir. Cardiovasc., 4(1): $51-63,1989$.

de várias maneiras. Podemos ter sucesso angiocardiográfico, hemodinâmico, ecocardiográfico e funcional. O sucesso angiocardiográfico é observado pela injeçāo de contraste em átrio esquerdo ( $\mathrm{AE})$, ventrículo esquerdo (VE) e aorta ascendente. Pelo $\mathrm{AE}$, podemos observar a demora, ou não, da passagem do contraste para o VE; já a injeção no VE nos dá a presença, ou não, de insuficiência mitral pelo procedimento e a passagem do contraste para aorta, nos casos de valvoplastia aórtica. A injeção na aorta nos mostraria o grau de competência da valva aórtica.

A subjetividade da análise desses dados a torna complemento dos outros, nāo devendo ser usada como única. É importante para a análise daș insuficiências que possam ter sido causadas, ou aumentadas, pela dilatação.

O sucesso funcional é observado tardiamente e se baseia na melhoria da sintomatologia do paciente. Também pode ser questionado pela subjetividade, já que alguns pacientes, como 1 de nossa série, onde não se obteve, por outros métodos, melhora alguma, ficam assintomáticos.

Os sucessos hemodinâmico e ecocardiográfico é que, realmente, são de maior valor e que devem ser bem estudados. Antes, durante e após os procedimentos, as pressōes podem ser medidas, bem como o débito cardiaco e os gradientes entre as câmaras. Com eles, podemos fazer cálculos da área valvar, ou determinar a queda de gradientes. Quanto deve cair este gradiente, ou quanto deve aumentar a área valvar não está bem padronizado. WILKINS et alii ${ }^{48}$ consideram sucesso área valvar maior que $1 \mathrm{~cm}^{2}$, pressão de $A E$ menor que 10 $\mathrm{mmHg}$ e área valvar final $25 \%$ maior que a inicial. A medida da área valvar é baseada em quase todas as publicações na fórmula de GORLIN \& GORLIN ${ }^{15}$, descrita em 1956, e que leva em consideraçāo o fluxo através da valva e a pressão capilar pulmonar para a mitral e a pressão de VE para a aorta. HAKKI et alii ${ }^{17}$, em 1981 , simplificaram a fórmula e, para a área valvar aórtica, usam o quociente entre o débito cardíaco e a raiz quadrada do gradiente de pressão da valva aórtica. HILLIS \& WINNIFORD ${ }^{21}$ fizeram a correlação da fórmula de Gorlin com a de Hakki e encontraram bons resultados, a não ser para freqüências abaixo de 65 ou acima de 100 batimentos por minuto.

O estudo ecocardiográfico com o emprego de Doppler tem sido de bastante valia, principalmente por poder ser repetido quantas vezes for necessário, sem risco para o paciente. A medida da área valvar antes e após o procedimento, a medida do tanıanho do AE e a graduação do gradiente, ou do grau de insuficiência, se presentes, podem nos dar uma boa visão do sucesso imediato bem como a longo prazo.

LITVACK et alii ${ }^{27}$ preconizam que os estudos sejam feitos, nāo só no momento do procedimento, mas tam- bém 24 e 48 horas depois, uma vez que, sem seu estudo, fazendo análise com Doppler nas 24 e 48 horas após a VAP, encontraram gradientes significativamente maiores que os medidos no laboratório de hemodinâmica.

COMMEAU et alii ${ }^{10}$ fizeram estudos semelhantes também em aórticos, mas, após 8 dias, encontraram aumento de gradiente e diminuiçāo da área valvar, resultados comparados com as medidas feitas no momento da dilatação.

REID et alii ${ }^{38}$, analisando, ecocardiograficamente, pacientes submetidos a valvoplastia mitral, estudaram o grau de abertura das comissuras e o ângulo formado nessas comissuras, considerando que há bom resultado em muitos casos, principalmente nos de boa mobilidade, pouca calcificação e sem o aparelho subvalvar comprometido, mas acham que a estimativa da área valvar pós procedimento tem valor limitado, já que encontraram boa correlação entre seus achados e os do cateterismo. Isso talvez ocorra devido a pequenos shunts esquerda-direita não detectados pela oximetria, ou a problemas inerentes ao método de Doppler empregado.

Baseados nessas análises de sucesso, os resultados obtidos por vários grupos, em todo o mundo, têm sido publicados.

HERMANN et alii ${ }^{20}$ realizaram 60 procedimentos de VMP em 49 pacientes, obtendo $62 \%$ de ótimos resultados, $35 \%$ de sub-ótimos e, em $3 \%$, não conseguiram atravessar o septo. Consideraram como sub-ótimo uma área valvar de $1 \mathrm{~cm}^{2}$, ou menos, gradiente mitral de $10 \mathrm{mmHg}$, ou mais, e aumento da área valvar de $25 \%$, ou menos. Como preceitos importantes para a obtençāo de bons resultados, ou não, citam o escore ecocardiográfico, a fibrilação atrial e a relação entre a área valvar e a superfície corporal.

COME et alii ${ }^{9}$ relatam 37 pacientes nos quais realizaram VMP, conseguindo um aumento de área valvar de $0,9 \mathrm{~cm}^{2}$ para $1,8 \mathrm{~cm}^{2}$.

PALACIOS et alii ${ }^{36}$ descrevem a valvoplastia mitral em 35 pacientes, obtendo diminuição do gradiente de 18 para $7 \mathrm{mmHg}$, aumento do débito cardiaco de 3,9 para 4,6 litros por minuto e aumento da área valvar de 0,8 para $1,7 \mathrm{~cm}^{2}$. Acreditam que a estrutura subvalvar comprometida no processo possa interferir no resultado.

McKAY ${ }^{30}$ relata sua experiência com 63 pacientes submetidos a VMP. Em 4 pacientes, năo conseguiu passar o septo e os pacientes foram encaminhados à cirurgia, onde se realizou substituição das valvas. Nos restantes, usou um único balão em 35 e duplo balăo em 21 pacientes. Obteve melhora na área valvar de 0,9 para $1,9 \mathrm{~cm}^{2}$, o gradiente diminuiu de 15 para $7 \mathrm{mmHg}$, o débito cardiaco aumentou de 4,2 para 5,1 litros por minuto e a pressão de átrio esquerdo diminuiu de 24 para $15 \mathrm{mmHg}$, Ocorreram 1 óbito imediato e 3 tardios, além 
ARNONI, A. S.; SALERNO, P. R.; HENRIQUES NETO, A. T. M.; DINKHUYSEN, J. J.; CHACCUR, P.; ABDULMASSIH NETO, C.; NAVARRO, S. L.; ESTEVES, C. A.; RAMOS, A. I. O.; SOUSA, J. E. M. R.; JATENE, A. D.; SOUZA, L. C. B.; PAULISTA, P. P. - O papel do cirurgião nas valvopatias reumáticas tratadas com valvoplastia percutânea. Rev. Bras. Cir. Cardiovasc., 4(1): $51-63,1989$.

da necessidade de substituição valvar em 2 casos. Nos demais pacientes, em seguimento de 6 meses, que considera pequeno, não houve reestenose.

LOCK et alii ${ }^{28}$ realizaram a VMP em 8 pacientes e o estudo com cateterismo, 8 semanas depois, mostrou persistência da melhoria obtida, com reestenose parcial em 1 caso.

BABIC et alii ${ }^{3}$ publicam resultados de 3 pacientes, nos quais empregaram técnica transarterial, obtendo meIhoria da área valvar e diminuição do gradiente transvalvar. Clinicamente, os pacientes estāo bem, 3 meses após o procedimento, e deverão ser reestudados angiograficamente com 12 meses.

Em nosso Serviço, 26 pacientes foram tratados com VMP e o sucesso foi obtido em 14 deles, com diminuição do gradiente ao estudo hemodinâmico e aumento da área valvar ao ecocardiograma. Todos estão com resultado mantido pela análise clínica, em uma evolução de 7,8 meses.

Da mesma forma que para a mitral, os trabalhos sobre valvoplastia aórtica têm sido publicados em grande número.

ROCHA et alii $^{41}$ trataram 24 pacientes pela VAP. com idade média de 79 anos (59 a 89), divididos em 2 grupos de 12 . No primeiro grupo, usaram balăo de diâmetro menor que $\mathrm{o}$ anel aórtico, e obtiveram redução do gradiente de 76 para $30 \mathrm{mmHg}$. No segundo, usaram o balāo trefoil e obtiveram redução maior no gradiente. Acreditam que o uso de balão maior que o anel aórtico possa dar melhores resultados. Ocorreram 3 óbitos imediatos, 4 tardios e 4 pacientes ( 2 de cada grupo) permaneceram em grau funcional IV da classificação de NYHA.

MARIO et alii ${ }^{29}$ analisaram 8 pacientes, nos quais realizaram a VAP. Em 1, não conseguiram, devido a dificuldades técnicas; em 2, houve necessidade de substituição valvar por recorrência da sintomatologia e reestenose e, em 5 , melhora clínica persiste após 4 meses.

LITVACK et alii ${ }^{27}$ descrevem 24 pacientes com idade média de 80 anos (51 a 90), submetidos a VAP. Ocorreu um óbito imediato. No primeiro seguimento de 22 semanas, 9 pacientes estavam em classe II, 4 em classe III e 3 na classe IV. Seis pacientes foram operados, com 1 óbito, um outro teve morte súbita e outro morreu na UTI, pouco após o procedimento. Ao final de 32 semanas, 6 pacientes estavam na classe II, 2 na classe III e 4 na classe IV. Nessa ocasiāo, 7 já haviam sido encaminhados à subsitituiçāo valvar e 6 tinham falecido, sendo 1 após a cirurgia. Desta forma, dos 24 pacientes, apenas 7 mantinham a melhora de pelo menos uma classe funcional, na classificação da NYHA.

BLOCK \& PALACIOS ${ }^{7}$ analisaram os 90 pacientes com a idade média de 79 anos (52 a 95), em que fizeram
VAP. Houve 8 óbitos hospitalares e 1 paciente foi perdido no seguimento tardio. Dos 81 remanescentes, 23 foram a óbito tardio. Calculam a reestenose como sendo de $56 \%$ (45 dos 81 pacientes) e, para isso, consideram como reestenose os 23 que foram a óbito, os 20 que estão em classe funcional IV e 2 que tinham reestenose ao cateterismo. Os melhores resultados foram obtidos naqueles em que a área valvar foi maior que $0,7 \mathrm{~cm}^{2}$ após o procedimento.

Um dos trabalhos de maior casuística é o de Mc$\mathrm{KAY}^{30}$, descrevendo 125 pacientes, com idade média de 76 anos, submetidos a VAP. Houve 50 óbitos hospitalares. $\mathrm{Na}$ evoluçāo tardia, 15 pacientes faleceram, 10 necessitaram substituição valvar e 10 têm reestenose documentada por angiocardiografia. Os 85 restantes estão bem, mas apenas pouco mais da metade tem 6 meses de seguimento.

LETAC et alii ${ }^{26}$ apresentam 218 pacientes submetidos a VAP. Em 6 casos, não houve mudança. Houve 1 óbito na sala de hemodinâmica, 9 óbitos logo após o procedimento e 9 precisaram de cirurgia. No seguimento clínico médio e 8 meses, de 144 pacientes, ocorreram 24 óbitos e, dos restantes $120,84 \%$ obtiveram meIhora. Cinqüenta e seis pacientes de sua série foram reestudados, sendo que 45 nāo tinham sintomas e 11 por agravamento da sintomatologia. A reestenose foi definida como a perda de $50 \%$, ou mais, dos benefícios pela dilatação. Como o objetivo do exame era determinar o grau de reestenose, dos 45 pacientes do primeiro grupo, consideraram apenas 37 pacientes que tinham dilatação eficiente (aumento maior que $25 \%$ da área valvar). Destes, 28 permaneceram sem reestenose e 9 (24\%) tinham reestenose importante. Dos 11 pacientes estudados por agravamento dos sintomas, todos tinham reestenose.

A nossa experiência é pequena e consta de apenas 1 paciente, que apresentou melhora imediata do gradiente, mas que foi internado 1 semana depois, com piora da sintomatologia, ficando internado até vir a óbito, 1 mês após a dilatação, em insuficiência cardiaca refratária ao tratamento.

Resta-nos discutir as complicações que podem ocorrer durante a realizaçāo dos métodos, quer decorrentes da técnica utilizada, quer pela dilatação propriamente dita. Em algumas dessas complicaçōes, os cirurgiōes precisam atuar e é devido a elas que existe a necessidade da equipe cirúrgica ficar de prontidão. Algumas vezes, as complicaçōes são pequenas, têm repercussōes temporárias, que não necessitam correçōes. Outras vezes, assumem grandes proporções, necessitando de uma rápida atuação para sua correção.

A abordagem da valva mitral através da técnica transeptal pode ser responsável por algumas dessas complicaçōes. Podemos ter acidentes embólicos, por desloca- 
ARNONI, A. S.; SAlERNO, P. R.; HENRIQUES Neto, A. T. M.; DINKHUYSEN, J. J.; CHACCUR, P.; ABDULMASSIH NETO, C.; NAVARRO, S. L.; ESTEVES, C. A.; RAMOS, A. I. O.; SOUSA, J. E. M. R.; JATENE, A. D.; SOUZA, L. C. B.; PAULISTA, P. P. - O papel do cirurgiăo nas valvopatias reumáticas tratadas com valvoplastia percutânea. Rev. Bras. Cir. Cardiovasc., 4(1): 51-63, 1989.

mento de trombo no átrio esquerdo. Isto seria mais comum nos portadores de fibrilação atrial. Preconiza-se o emprego de anticoagulantes nas 4 a 6 semanas anteriores ao procedimento, para evitar esse problema. Além disso, vários grupos contra-indicam a sua realização em pacientes com evidência de trombo em átrio esquerdo, ou com história de acidente embólico pregresso. São descritos desde distúrbios temporários de comportamento, até acidentes embólicos cerebrais graves.

Os acidentes embólicos podem ocorrer também por liberação de fragmentos de cálcio, como foi observado em dilataçōes experimentais, realizadas post-mortem, ou em valvas retiradas para substituição valvar.

Outra complicação descrita é a criação de um defeito septal atrial, considerado por alguns como a mais freqüente delas. A necessidade da passagem dos cateteres-balão pelo septo obriga à abertura do septo, que pode permanecer sem se fechar depois da retirada dos mesmos. A retirada do balão, mesmo desinsuflado, pode também ser responsável por esse defeito. A deterioração hemodinâmica em decorrência disso não parece ser grande, mas, a longo prazo, não se conhece sua repercussão, ou a possibilidade de embolias paradoxais, como refere McKAY ${ }^{30}$. Todos os grupos descrevem uma porcentagem relativamente grande de defeitos septais, nem sempre detectados pelo estudo contrastado, ou oximétrico, mas perceptiveis pelo ecocardiograma.

Uma complicação mais grave é o tamponamento cardiaco provocado por perfuraçōes do átrio, tanto direito como esquerdo, ou dos ventrículos. Podem ocorrer por uma punção inadequada do septo, levando à perfuração do átrio direito, ou por mau posicionamento dos guias, levando à perfuraçāo do ventrículo. $\mathrm{O}$ tamponamento precisa ser diagnosticado de imediato e o paciente deve ser levado logo à sala cirúrgica, ou ter seu pericárdio drenado na própria sala de hemodinâmica e, em seguida, encaminhado à cirurgia.

Outra complicação que necessita da atuação do cirurgião é a insuficiência mitral provocada, ou por laceração das cúspides ou por rotura dos músculos papilares. Acredita-se que esses problemas possam surgir por má escolha do tamanho do balão, ou por posicionamento inadequado do balão através das cordas tendíneas. As grandes insuficiências não são comuns, mas pequenos aumentos no grau de regurgitaçāo das valvas são descritos com maior frequeência, chegando, em alguns Serviços, a $50 \%^{20}$.

A simples punção da aorta é uma complicação menos séria, pois o calibre da agulha não causa problemas. Mas o seu diagnóstico tem que ser preciso, pois a continuação do método pode levar a consequeências graves. Mais importante é a perfuraçâo da aorta, levando a hematomas, ou mesmo derrames sangüíneos no pericárdio,que, normalmente, são de pequena quantidade, mas que podem chegar ao tamponamento, se não corrigidos.
Outra complicaçăo descrita, mas também em menor número, são as endocardites nas valvas tratadas. BLOCK et alii ${ }^{8}$ descrevem casos em que o paciente veio a óbito por septicemia pós drenagem de abscesso dentário. $A$ análise da valva tratada não mostrava sinais de infecção.

Alguns problemas são relacionados às punçōes, como grandes hematomas, sangramentos, tromboses, ou até pseudo-aneurisma nas artérias femorais e que, às vezes, necessitam correção cirúrgica, nem sempre fácil, pois sua correção é dificultada pelos hematomas que alteram os planos cirúrgicos.

Alteraçōes de ritmo, desde fibrilação atrial transitória até bloqueio atrioventricular total, necessitando implante de marcapasso definitivo, podem ocorrer.

Em nossa série, tivemos 4 complicaçōes nos pacientes com sucesso, sendo 1 distúrbio de comportamento, 1 acidente vascular cerebral com seqüela, 1 parada cardíaca recuperada sem seqüela e 1 abdome agudo por hematoma de retroperitônio, causada por lesão venosa. Dos que necessitaram correção cirúrgica, houve 1 caso de tamponamento por perfuração do átrio e do ventrículo direito; 1 rotura de músculo papilar e 4 punçōes da aorta, 2 dos quais com hematoma na parede da aorta, mas sem perfuraçāo para a cavidade pericárdica.

A reestenose, complicação tardia mais freqüente, já foi discutida anteriormente, mas o pouco tempo de seguimento dos pacientes tratados com valvoplastias faz com que sua análise seja precoce.

A valvoplastia aórtica percutânea tem como principal complicação a insuficiência aórtica, que, quando importante, pode ser de graves conseqüências, necessitando correção imediata. A rotura de uma válvula pode ser responsável por ela.

Os fenômenos embólicos por deslocamentos de fragmentos de cálcio também podem ocorrer. Entretanto, sua incidência não parece grande e não foram comprovados por tomografia.

Complicaçōes semelhantes às das VMP são relatadas, como distúrbios de ritmo, traumas vasculares nas artérias periféricas, desde hematomas até pseudo-aneurismas, necessitando correção cirúrgica.

O tamponamento também pode acontecer, ou por perfuração do ventrículo esquerdo, ou, ainda, por dissecção aórtica. A rotura da aorta por emprego de balão de dimensōes maiores que $c$ anel foi relatada por WALLER et alii ${ }^{47}$.

A hipotensão severa tem sido observada durante a insuflação do balão $e$, às vezes, não melhora com a desinsuflação. $O$ aumento de pressão no ventrículo esquerdo, em insuflaçōes anteriores, seria o responsável 
ARNONI, A. S.; SALERNO, P. R.; HENRIQUES NETO, A. T. M.; DINKHUYSEN, J. J.; CHACCUR, P.; ABDULMASSIH NETO, C.; NAVARRO, S. L.; ESTEVES, C. A.; RAMOS, A. I. O.; SOUSA, J. E. M. R.; JATENE, A. D.; SOUZA, L. C. B.; PAULISTA, P. P. - O papel do cirurgiấo nas valvopatias reumáticas tratadas com valvoplastia percutânea. Rev. Bras. Cir. Cardiovasc., 4(1): 51-63, 1989.

por isto. A resposta vagal levando a bradicardia e hipotensão também são notadas.

Outra complicação citada é a laceração da cúspide mitral quando da realizaçāo da VAP, como ocorreu em 1 caso de LITVACK et alii ${ }^{27}$.

A infecção levando a septicemia e morte foi descrita por LETAC et alii ${ }^{26}$, em 2 de seus casos. Outro de seus pacientes foi a óbito por hemorragia interna causada por rotura de um dos ramos da aorta, em paciente que apresentava grande tortuosidade das artérias.

Se a reestenose é a complicação tardia mais importante para as VMP, ela ganha maior destaque para as da valva aórtica, normalmente realizadas em pacientes mais idosos, quase sempre com grandes calcificações. $\mathrm{O}$ índice de reestenose é muito grande e, como já vimos, 8 dias após, os resultados já são bem piores que os obtidos no momento do procedimento.

\section{CONCLUSÕES}

Os resultados das valvoplastias mitrais estāo bastante condicionados a uma boa seleção das valvas a serem tratadas. A mobilidade das cúspides, a presença, ou não, de calcificação, a espessura das cúspides e o comprometimento das estruturas subvalvares desempenham papel importante a curto e longo prazo. A boa evolução dos pacientes submetidos a correção cirúrgica, com visão direta das valvas, faz com que a evolução tardia dos pacientes submetidos a VMP seja esperada, para uma análise mais adequada. Ela tem evidente indicaçāo em pacientes de alto risco cirúrgico, ou naqueles que, por problemas gerais, nāo possam receber próteses metálicas ou biológicas. Mas a análise apurada do tipo de valva a ser tratada deve ser realizada, pois valvas com grande calcificaçāo ou com grande fusāo das estruturas subvalvares serão mais beneficiadas, ou com a substituição valvar, ou com abertura das comissuras e papilares.

Já as valvoplastias aórticas, no estágio atual, devem ser consideradas como paliativas e limitadas a pacientes de alto risco, ou que recusem o tratamento cirúrgico.

RBCCV 44205-77

ARNONI, A. S.; SALERNO, P. R.; HENRIQUES, NETO, A. T. M.; DINKHUYSEN, J. J.; CHACCUR, P.; ABDULMASSIH NETO, C.; NAVARRO, S. L.; ESTEVES, C. A.; RAMOS, A. I. O.; SOUSA, J. E. M. R.; JATENE, A. D.; SOUZA, L. C. B.; PAULISTA, P. P. - The role of the surgeon in percutaneous valvuloplasty. Rev. Bras. Cir. Cardiovasc., 4(1): 51-63, 1989.

ABSTRACT: Since August 1987, at the Instituto Dante Pazzanese de Cardiologia (IDPC) percutaneous mitral and aortic valvuloplasty was performed in 27 patients. In 26 for mitral and in 1 for aortic valve disease. In 26 patients mitral valvuloplasties success was accomplished in 14 patients. From those we had some complications in 4 . The success was not total in 3 patients. One patient with mitral insufficiency refused surgery; the second one underwent surgery, and the third one is assymptomatic but without increase in valve area or drop in the gradient and will be reviewed. The last 9 patients underwent surgery. Six underwent commissurotomy and papilotomy and 3 , valve replacement. The surgical indications were: cardiac tamponade in one, papilary muscle rupture in another one, low cardic output in 1 and puncture of the aorta in 4 cases. The catheter did not reach the left atrium in the last 2 cases and the hypothesis of cardiac tamponade was suspected, but not confirmed. The patient who underwent aortic valvuloplasty had the gradient dropped, but died one month later, in heart failure. Percutaneous valvuloplasty is an alternative treatment for patients with mitral or aortic valve stenosis without calcification or alterations of the subvalvar apparatus, mainly in those cases in which the surgery is of high risk like the elderly, in patient with renal and chronic lung diseases.

DESCRIPTORS: percutaneous valvuloplasty, surgery; heart valves, surgery.

\section{REFERÊNCIAS BIBLIOGRÁFICAS}

1 AL, ZAGAIB, M.; KASAB, S.; RIBEIRO, B. A.; AL FAGIH, M. R. - Percutaneous double balloon mitral valvotomy for the rheumatic mitral valve stenosis. Lancet, 1 : 757-761, 1986.
2 ARNONI, A. S.; ANDRADE, J.; FALCÃO, H. C. B.; SOUZA S. C. S.; DINKJUYSEN, J. J.; OLIVEIRA, J. B.; JATENE, A. D.; SOUZA, L. C. B.; PAULISTA, P. P. - Cirurgia cardiaca na gravidez. Rev. Bras. Cir. Cardiovasc. 1(1): 14-19, 1986. 
ARNONI, A. S.; SALERNO; P. R.; HENRIQUES NETO, A. T. M.; DINKHUYSEN, J. J.; CHACCUR, P.; ABDULMASSIH NETO, C.; NAVARRO, S. L.; ESTEVES, C. A.; RAMOS, A. I. O.; SOUSA, J. E. M. R.; JATENE, A. D.; SOUZA, L. C. B.; PAULISTA, P. P. - O papel do cirurgiāo nas valvopatias reumáticas tratadas com valvoplastia percutânea. Rev. Bras. Cir. Cardiovasc., 4(1): 51-63, 1989.

3 BABIC, U. U.: PEJCIC, P.; DJURISIC, Z; VUCINIC, M.; GRUJICIC, S. M. - Percutaneous transarterial balloon valvuloplasty for mitral valve stenosis. Am. J. Cardiol., 57: 1101-1104, 1986.

4 BAILEY, C. P. - The surgical treatment of mitral stenosis (mitral commissurotomy). Dis. Chest, 15: 377-384, 1949.

5 BAILEY, C. P.; REDONDO-RAMIREZ, H. P.; LARZERELE, H. B. - Surgical treatment of aortic stenosis. JAMA, 150: $1647-1652,1952$.

6 BLOCK, P. C. - Who is suitable for percutaneous balloon mitral valvotomy? Internat. J. Cardiol., 20: 9-14, 1988.

7 BLOCK, P. C. \& PALACIOS, I. F. - Clinical and haemodynamic follow-up after percutaneous aortic valvuloplasty in the elderly.. Am. J. Cardiol., 62: 760-763, 1988.

8 BLOCK, P. C.; PALACIOS, I. F.; JACOBS, M. L.; FALLON, J. T. - Mechanism of percutaneous mitral valvotomy. Am. J. Cardiol., 59: 178-179, 1987.

9 COME, P. C.; RIBLEY, M. F.; DIVER, D. J.; MORGAN, J. P.; SAFIAN, R. D.; MCKAY, R. G. - Non invasive assessment of mitral sienosis before and after percutaneous balloon mitral valvuloplasty. Am. J. Cardiol., 61: 817-825, 1988.

10 COMMEAU, P.; GROLLIER, G.; LAMY, E.; FOUCAULT, J. P.; DURAND, C.; MAFFEI, G.; MAIZA, D.; KHAIT, A.; POITIER, J. C. - Percutaneous balloon dilatation of calcific aortic valve stenosis: anatomical and haemodynamic evaluation. Br. Heart J., 59: 227-238, 1988.

11 CRIBIER, A.; SAOUDI, N.; BERLAND, J.; SAVIN, T.; ROCHA, P.; LETAC, B. - Percutaneous transluminal valvuloplasty of acquired aortic stenosis in elderly patients: an alternative to valve replacement? Lancet, 1 $63-67,1986$

12 CRIBIER, A.; SAVIN, T.; BERLAND, J.; ROCHA, P.; MECHMECHE, R.; SAOUDI, N.; BAHAR, P.; LETAC. B. - Percutaneous transluminal balloon valvuloplasty of adult aortic stenosis: report of 92 cases. J. Am. Coll. Cardiol., 9: 381-389, 1987.

13 CUTLER, E. C. \& BECK, C. S. - The present status of the surgical procedure in chronic valvular disease of the heart. Arch. Surg., 18: 403-416, 1929.

14 DORROS, G.; LEWIN, R. F.; KING, J. F.; JANKE, L. M - Percutaneous transluminal valvuloplasty in calcific aortic stenosis: the double balloon technique. Cathet. Cardiovasc. Diag., 13: 151-156, 1987. calculation of the area of the stenotic mitral valve, other cardiac valves, and central circulatory shunts: I. Am. Heart J., 41: 1-29, 1951.
16 HAMAD, N.; PICHARD, A.; LINDSAY, J. - Combined coronary angioplasty and aortic valvuloplasty. $A m$. J. Cardiol., 60: 1184-1186, 1987.

17 HAKKI, A. H.; ISKANDRIAN, A. S.; BEMIS, C. E.; KIMBIRIS, D.; MINTZ, B. S.; SEGAL, B. L.; BRICE, C. A simplfied valve formula for the calculation of stenotic cardiac valve areas. Circulation, 63: 1050-1055, 1981.

18 HARKEN, D. E.; ELLIS, L. B.; WARE, P. F.; NORMAN, L. R. - The surgical treatment of mitral stenosis: I. Valvuloplasty. N. Engl. J. Med., 239: 804-808, 1948

19 HAYS, L. J.; TEDESCO, C. L.; LEATHERMAN, G. F.; SMUCKER, M. L. - Successful combined percutaneous aortic balloon valvuloplasty and coronary angioplasty in two critically ill patients. Cathet. Cardiovasc. Diag., 14: 96-99, 1988.

20 HERMANN, H. C.; WILKINS, G. T.; ABASCAL, V. M.; WEY MAN, A. E.; BLOCK, P. C.; PALACIOS, T. F. - Percutaneous balloon mitral valvotomy for patients with mitral stenosis. J. Thorac. Cardiovasc. Surg., 96: 33-38, 1988.

21 HILLIS, L. D. \& WINNIFORD, M. D. - The simplified formula for the calculation of aortic valve area: potencial inaccuracies in patients with bradycardia or tachycardia. Cathet. Cardiovasc. Diag., 13: 301-303, 1987.

22 INOUE, K,; OWAKI, T.; NAKAMURA, T.; KITAMURA, F.; MIYAMOTO, N. - Clinical application of transvenous mitral commisurotomy by a new balloon catheter. J. Thorac. Cardiovasc. Surg., 87: 394-402, 1984

23 KAPLAN, J. D.; ISNER, J. M.; KARAS, R. H.; HALABURKA K. R.; KONSTAM, M. A.; HOUGEN, T. J.; CLEVELAND R. J.; SALEM, D. N. - In vitro analysis of mechanisms of balloon valvuloplasty of stenotic mitral valves. $A \mathrm{~m}$. J. Cardiol., 59: 318-323, 1987

24 LABABIDI, Z. \& WEINHAUS, L. - Successful balloon valvuloplasty for neonatal critical aortic stenosis. $A m$ Heart J., 112: 913-916. 1986.

25 LARZELERE, H. B. \& BAILEY, C. P. - New instrument for cardiac valvular commissurotomy. H, Thorac. Surg., 25: 78-81, 1953

26 LETAC, B.; CRIBIER, A.; KONING, R.; BELLEFLEUR, J. P. - Results of percutaneous transluminal valvuloplasty in 218 adults with valvular aortic stenosis. $A m$. J. Cardiol., 62: 598-605, 1988

27 LITVACK, F.; KAJUBOWSKI, A. T.; BUCHBINDER, N. A.; EIGLER, N. - Lack of sustained clinical improvement in an elderly population after percutaneous aortic valvuloplasty. Am J. Cardiol., 62: 270-275, 1988.

28 LOCK, J. E.; KHALILULLAH, M.; SHREVASTAVA, S. BAHL, V.; KEANE, J. F. - Percutaneous catheter commissurotomy in rheumatic mitral stenosis. En. Engl. J. Med., 313: 1515-1518, 1985. 
ARNONI, A. S.; SALERNO, P. R.; HENRIQUES NETO, A. T. M.; DINKHUYSEN, J. J.; CHACCUR, P.; ABDULMASSIH NETO, C.; NAVARRO, S. L.; ESTEVES, C. A.; RAMOS, A. I. O.; SOUSA, J. E. M. R.; JATENE, A. D.; SOUZA, L. C. B.; PAULISTA, P. P. - O papel do cirurgiấo nas valvopatias reumáticas tratadas com valvoplastia percutânea. Rev. Bras. Cir. Cardiovasc., 4(1): 51-63, 1989.

MARIO, C. D.; BEATT, K. J.; FEYTER, P.; VAN DEN BRAND, M.; ESSED, C. E.; SERRUYS, P. W. - Percutaneous aortic balloon dilatation for calcific aortic stenosis in elderly patients: immediate haemodynamic re- sults and short term follow-up. Br. Heart J., 58: 644-652, 1987

30 McKAY, R. G. - Balloon valvuloplasty for treating pulmonic, mitral and aortic valve stenosis. Am. J. Cardiol., 61: 102G-108G, 1988.

31 MCKAY, R. G.; SAFIAN, R. D.: BERMAN, A. D.: DIVER, D. J.; WEINSTEIN, J. S.; WYMAN, R. M.; SUNNINGHAM, M. J.; McKAY, L. L.; BAIM, D. S.; GROSSMAN, W. - Combined percutaneous aortic valvuloplasty and trasluminal coronary angioplasty in adult patients with calcific aortic stenosis and coronary artery disease. Circulation, 76: 1298-1306, 1987.

32 MCKAY, R. G.; SAFIAN, R. D.; LOCK, J. E.; MANDELL, V. S.; THURER, R. L.; SCHNITT, S. J.; GROSSMAN, W. - Balloon dilatation of calcific aortic stenosis in elderly patients: postmortem, intraoperative, and percutaneous valvuloplasty studies. Circulation, 74: $119-125,1986$

33 MEIER, B.; FRIEDLE, B.; OBERHAUSEN, J.; BELENGER, J.; FINCI, L. - Trefoil balloon for percutaneous valvuloplasty. Cathet. Cardiovasc. Diag., 12: 277-281, 1986.

34 PAGE, U. S.; OKIES, J. E.; COLBURN, L. Q.; BIGELOW, J. C.; SALOMON, N. W.; KRAUSE, R. H. - Percutaneous transluminal coronary angioplasty: a growing surgical problem. J. Thorac. Cardiovasc. Surg., 92: 847-852, 1986.

35 PALACIOS, I \& BLOCK, P. C. - Anterograde balloon valvotomy for aortic stenosis. J. Am. Coll. Cardiol., 9(2): 14A, 1987 (Resumo).

36 PALACIOS, I.; BLOCK, P. C.; BRANDI, S.; BLANCO, P.; CASAL, H.; PULIDO, J. L.; MUÑOZ, S.; D'EMPAIRE, G.; ORTEGA, M. A.; JACOBS, M.; VLAHAKES, G. Percutaneous balloon valvotomy for patients with severe mitral stenosis. Circulation, 75: 778-784, 1987.

37 PALACIOS, I. F.; BLOCK, P. C.; WILKINS, G. T.; REDIKER, D. E.; DAGGETT, W. M. - Percutaneous mitral balloon valvotomy during pregnancy in a patient with severe mitral stenosis. Cathet. Cardiovasc. Diag., 15: 109-111, 1988.

38 REID, C. L.; McKAY, C. R.; CHANDRARATNA, P. A. N.; KAWANISHI, D. T.: RAHIMTOOLA, S. H. - Mechanism of increase in mitral valve area and influence of anatomic features in double-balloon, catheter balloon valvuloplasty in adults with rheumatic mitral stenosis: a Doppler and two-dimensional echocardiographic study. Circulation, 76: 628-636, 1987.

39 RIBEIRO, P. A.; ZAGAIB, M.; RAJENDRAN, V.; ASHMEG, A.; KASAB, S.; FARAIDI, Y.; HALIM, M.; IDRIS, M.; FAGIH, M. R. - Mechanism of mitral valve area increase by in vitro single and double balloon mitral valvotomy. $A m$. J. Cardiol., 62: 264-269, 1988.
40 ROBICKSEK, F. \& HARBOLD, N. B. - Limited value of ballon dilatation in calcified aortic stenosis in adults: direct observations during open heart surgery. $\mathrm{Am}$. J. Cardiol., 60: 857-864, 1988.

41 ROCHA, P.; BARON, B.; LACOMBE, P.; BERNIER, A.; KAHN, J. C.; LIOT, F.; BOURDARI, J. P. - Aortic percutaneous transluminal valvuloplasty in elderly patients by balloon larger than aortic anulus. Cathet. Cardiovasc., Diag., 15: 81-88, 1988.

42 ROUSSEAU, M. F.; WINS, W.; HAMMER, F.; CAUCHETEUX, D.; HUE, L.; POULEUR, H. - Changes in coronary blood flow and myocardial metabolysm during aortic balloon valvuloplasty. Am. J. Cardiol., 61: 1080-1084, 1988.

43 RUPPRATH, G. \& NEUHAUS, K. L. - Percutaneous balloon valvuloplasty for aortic valve stenosis in infancy. Am. J. Cardiol., 55: 1655-1656, 1985.

44 SAFIAN, R. D.; BERMAN, A. D.; SACHS, B.; DIVER, D. J.; COME, P. C.; BAIM, D. S.; MCKAY, L.; GROSSMAN W.; McKAY, R. G. - Percutaneous balloon mitral valvuloplasty in a pregnant woman with mitral stenosis. Cathet. Cardiovasc. Diag., 15: 103-108, 1988.

45 UBAGO, J. L. M.; PRADA, J. A. V. BARDAJI, J. L.; COLMAN, T.; FIGUEIROA, A.; MARTIN-DURAN, R.; GOMEZ-DURAN, C. M. - Percutaneous balloon valvulotomy for calcific rheumatic mitral stenosis. $A m$. J. Cardiol., 59: 1007-1011, 1987.

46 VANDERMAEL, A. M.; DELIGOUNUL, U.; GABLIANI, G.; CHAITMAN, B.; KERN, M. J. - Percutaneous balloon valvuloplasty and coronary angioplasty for the treatment of calcific aortic stenosis and obstructive coronary artery disease in an elderly patient. Cathet. Cardiovasc. Diag., 14: 49-52, 1988.

47 WALLER, B. F.; GIROD, D. A.; DILLON, J. C. - Transverse aortic wall tears in infants after balloon angioplasty for aortic valve stenosis: relation of aortic wall damage to diameter of inflated angioplasty balloon and aortic lumen in seven necropsy cases. J. Am. Coll. Cardiol., 44: 1235-1241, 1984.

48 WILKINS, G. T.; WEYMAN, A. F.; ABASCAL, V. M. BLOCK, P. C.; PALACIOS, I. F. - Percutaneous balloon dilatation of the mitral valve: an analysis of echocardiographic variables related to outocome and the mechanisms of dilatation. Br. Heart J., 60: 299-308, 1988.

\section{Dicussão}

DR. JORGE BÜCHLER

São Paulo, SP

Agradeço o honroso convite para participar deste importante everito e comentar este excelente trabalho. Em 1986, quando introduzi, em nosso País, as técnicas 
ARNONI, A. S.; SALERNO, P. R.; HENRIQUES NETO, A. T. M.; DINKHUYSEN, J. J.; CHACCUR, P.; ABDULMASSIH NETO, C.; NAVARRO, S. L.; ESTEVES, C. A.; RAMOS, A. I. O.; SOUSA, J. E. M. R.; JATENE, A. D.; SOUZA, L. C. B.; PAULISTA, P. P. - O papel do cirurgiâo nas valvopatias reumáticas tratadas com valvoplastia percutânea. Rev. Bras. Cir. Cardiovasc., 4(1): 51-63, 1989.

de valvoplastia mitral e aórtica em laboratório de cateterismo, tive, também, a oportunidade de realizar, juntamente com o Dr. Arnoni, alguns casos em sala de cirurgia, na tentativa inicial de entender o mecanismo de ação do balāo insuflado na valva estenótica. O presente trabalho me parece bastante oportuno e mostra a importância de um time cirúrgico de prontidão e sua atuação diante de complicaçōes que poderiam ser fatais, caso não fossem prontamente tratadas. Qualquer método novo exige do operador uma crescente experiência e, muito importante, um extremo bom senso para ponderar até onde suas limitaçōes diante de um determinado caso poderia evitar uma complicação maior. Em junho de 1987, reiniciei, agora no Hospital da Beneficiência Portuguesa de São Paulo, uma nova etapa nesta terapêutica. Desde essa época, já realizamos aproximadamente 70 procedimentos para a valva mitral e 50 para a valva ab́rtica. A valvoplastia mitral tem sido realizada, de preferência, pela técnica transeptal, reservando-se a técnica transarterial isolada para alguns casos especiais. Importante salientar que a nossa técnica transarterial é bastante diferente daquela introduzida por Babic e colaboradores, que introduz os guias pela técnica transeptal dentro da aorta, puxando-os por punção de artéria femoral, para posterior introduçāo dos balōes por essa via arterial. Tanto na técnica de Babic, quanto na nossa, é utilizado, no momento, o duplo-balāo, com a diferença que Babic utiliza um balão em cada artéria femoral e nós intoduzimos os 2 balōes pela mesma artéria femoral e pelo mesmo ponto de punção. Importante é salientar que a quase totalidade dos nossos casos foi realizada após as 22 horas, o que, por si só, já poderia representar um fator de risco a mais. Para nossa felicidade, não tivemos nenhuma complicação relacionada à técnica transeptal propriamente dita e nenhuma cirurgia de emergência se fez necessária. Os resultados imediatos têm sido bastante bons e estão diretamente relacionados às condiçōes da valva e do aparelho subvalvar, calcificação e fibrilação atrial. Os resultados, a curto e médio prazo, são animadores, porém um seguimento a longo prazo é necessário, para comparação com os resultados obtidos na comissurotomia cirúrgica. As únicas contra-indicaçōes para esse procedimento estariam relacionadas à presença de trombo no átrio esquerdo e à história de embolia prévia. Na valvoplastia aórtica, embora os resultados imediatos tenham sido bastante satisfatórios, o seguimento, a curto e médio prazo não tem sido tâo otimista, devido à alta incidência de reestenose e óbitos tardios, como observados na literatura mundial. Não tivemos, também, nenhuma complicação relacionada a óbito imediato, ou cirurgia de emergência. As indicaçōes para este procedimento,no presente momento, são: 1) pacientes idosos com alto risco cirúrgico; 2) doenças associadas que contra-indiquem a cirurgia; 3 ) cirurgia não cardiaca de emergência; 4) pacientes com baixa fração de ejeção como preparo para cirurgia. Em suma, parece-me bastante lógico considerar a valvoplastia com balāo um procedimento alternativo à cirurgia com grande potencial de crescimento, devendo ser, no entanto, associada a baixos índices de complicações e melhora significativa do quadro clínico, bem como grande durabilidade. Não devemos esquecer que, no momento atual, a cirurgia é, ainda, o tratamento de escolha nas doenças valvares.

\section{DR. EULÓGIO MARTINEZ FILHO \\ São Paulo, SP}

Excelente o trabalho do Dr. Arnoni, porque é sobre um assunto de extrema importância, que enfatiza a grande responsabilidade que nós temos, hoje, de propor a um paciente um procedimento com esse potencial de risco, em face de uma cirurgia que atingiu, em nosso meio, um risco praticamente despresível, com o aperfeiçoamento das técnicas e treino das equipes; entāo, é sempre uma situaçăo de grande responsabilidade. Eu estive nos Estados Unidos, para aprender a realizar a técnica e com a finalidade de trazer o professor que veio à Escola Paulista de Medicina e conosco dilatou 7 pacientes, sem nenhum acidente, e, depois disso, nós agora na semana passada, dilatamos 1 paciente, usando toda a técnica, também sem nenhum acidente. Então, vou aproveitar esta oportunidade para compartilhar com os colegas. É mais um assunto especificamente hemodinâmico, que já, inclusive, apresentei em um congresso de hemodinâmica; são 3 ou 4 aspectos práticos, que são importantíssimos, especialmente em relação à punçāo transeptal; em primeiro lugar, toda vez que se introduz a agulha, ela é feita, obviamente, através de um fio condutor que é colocado na veia cava superior, o fio é retirado e se tenta puncionar o septo descendo com a agulha; se não se consegue a punção, a agulha deve ser retirada e, novamente, introduzida no fio condutor; nós o vimos fazer, aqui, 5 ou 6 vezes esse procedimento; as perfurações de cava, as perfuraçōes de átrio direito acontecem quando nāo se consegue perfurar o septo e se tenta reposicionar a agulha em uma posição mais cefálica; é muito importante, com relação à punção da aorta, quando se punciona a aorta, quando se erra a punção transeptal e se atinge a aorta, ai o coração batendo pode rasgar a aorta; que cuidado se deve tomar? É intuitivo que se tenta puncionar a aorta olhando para a tela; essa punção deve ser feita olhando o monitor de pressão, então a qualidade fásica da pressão de átrio direito deve ser excelente, porque o indivíduo exterioriza a agulha e olha para a curva de pressão; se esta nāo aparece, ele imediatamente puxa a agulha para fora. Em relação à rotura de papilares e à rotura do anel valvar, é uma recomendação enfática desse grupo, de que se coloquem as extremidades dos 2 fios condutores que vão guiar o balão, na aorta descendente, fazendo um 8 , ou seja indo até o ápice do ventrículo esquerdo, voltando sobre si mesmo, saindo pela aorta ascendente, evita-se que o cateter entre pelo átrio esquerdo, atra- 
ARNONI, A. S.; SALERNO, P. R.; HENRIQUES NETO, A. T. M.; DINKHUYSEN, J. J.; CHACCUR, P.; ABDULMASSIH NETO. C.; NAVARRO, S. L.; ESTEVES, C. A.; RAMOS, A. I. O.; SOUSA, J. E. M. R.; JATENE, A. D.; SOUZA, L. C. B.; PAULISTA, P. P. - O papel do cirurgião nas valvopatias reumáticas tratadas com valvoplastia percutânea. Rev. Bras. Cir. Cardiovasc., 4(1): $51-63,1989$

vesse a valva mitral e saia pela aorta, sem fazer uma curva curta, porque, se ele vai até a ponta do ventrículo esquerdo, a chance de impactar no aparelho subvalvar fica extremamente menor. O procedimento que esse professor fez aqui demorou 4 a 5 horas, quer dizer, é um procedimento extremamente demorado, mas esses 3 aspectos são muito importantes, com relação à punção septal, ao cuidado de reposicionar a agulha na cava e à forma de 2 fios condutores em relação à via de posicionamento dos balōes. Nós temos uma experiência muito curiosa, que é trabalho que realizamos com esse grupo de pacientes; temos um fisiologista de exercício, muito capaz, e eu imaginei que esse fosse um material muito interessante para uma experiência que seria analisar um impacto do alívio instantâneo da resistência do fluxo, sem que haja mudança no estilo de vida, ou agressão ao pós-operatório; então, o que nós fizemos, nesse grupo de pacientes, foi submetê-lo a um exercício programado, como medida direta do consumo de oxigênio, determinação do limiar aeróbico e consumo máximo de oxigênio na véspera e 2 a 3 dias depois do procedimento; isto é muito curioso, porque, quando o Dr. Arnoni se refere ao resultado funcional, muitas vezes, realmente, os aspectos angiográfico e ecocardiográfico de persistência de uma fusão subcomissural não impedem que esses pacientes atinjam nivel de exercício muito mais intenso. Os pacientes foram reestudados, 6 meses depois, em termos desse argumento, e mantêm esse bom resultado funcional. Era o que eu gostaria de dizer. Muito obrigado.

\section{DR. FRANCISCO COSTA Curitiba, $P R$}

Agadeço a oportunidade de comentar o trabalho e cumprimentar o Dr. Arnoni pela excelência da exposição. Na Santa Casa de Curitiba, onde existe um grupo bastante agressivo, em termos cirúrgicos, foram realizadas, a partir de maio de 1987, até fevereiro de 1989 , 19 valvoplastias percutâneas mitrais. Os pacientes foram bastante estritos nos critérios de indicação, seguindo, exatamente, idade inferior abaixo de 35 anos, com acento sintomático, ritmo sinusal, escore abaixo de 8 e a cirurgia cardíaca prévia não contra-indicou o procedimento; foram considerados com sucesso 17 pacientes e 2 apresentaram insucesso; em 1, houve tamponamento por perfuração do átrio direito, foi levado à cirurgia, outro, também com suspeita de tamponamento, foi à cirurgia, mas não havia tamponamento, foi feita uma comissurotomia mitral; há, também, outro paciente que está em lista para cirurgia. O tratamento cirúrgico da estenose mitral, através da toracotomia lateral direita é, hoje, um procedimento bem estabelecido, o risco operatório é menor que $1 \%$, a morbidade não tem sido importante; durante a operação, é possivel analisar com todos os detalhes os componentes do aparelho valvar a atuar sobre eles de maneira precisa, ou seja, abrir comissuras, fazer papilarotomias, fenestraçāo de cordas, descalcificação, etc.; após completar o procedimento, a valva é testada e insuficiências mitrais residuais podem ser devidamente corrigidas; já a valvoplastia percutânea com balão assemelha-se à comissurotomia fechada; é possível aumentar a área valvar, na maioria dos casos, através da abertura das comissuras; entretanto, o apareIho subvalvar nāo é convenientemente tratado e a criação da insuficiência dessa valva não está sob controle do operador; assim, achamos que o procedimento não seja tão efetivo e seguro como a comissurotomia mitral e os resultados, a longo prazo, também não devam ser semelhantes; pensamentos semelhantes a esses foram expressos por Spencer, no editorial do Journal of Cardiovascular Surgery, em 1988; por outro lado, não podemos esquecer que, em nosso meio, é muito freqüente depararmos com um paciente adolescente sintomático com semiologia clássica e estenose mitral e que necessita de uma comissurotomia, digamos aos 16 anos de idade; esse paciente volta após, 8, 10, 12 anos, para uma segunda cirurgia, eventualmente para uma comissurotomia e, novamente, para uma terceira, uma prótese valvar, depois disfunções valvares, etc.; então, achamos que, aqui, é o papel da valvoplastia e, no paciente rigorosamente selecionado, poderiamos, eventualmente, adiar para mais tarde a evolução da doença, a primeira cirurgia do paciente. Muito obrigado.

\section{DR. ARNONI \\ (Encerrando)}

Penso que a única coisa que eu temo um pouco é que o papilar seja mais prejudicado por essa técnica do que pela outra. Ela tem, evidentemente, algumas vantagens, com relação à primeira, mas o mau posicionamento do balão pode provocar uma rotura de papilares; evidentemente que isto é uma curva de aprendizado, algumas das complicações vão diminuir, mas eu não acredito que a $\mathrm{CIA}$ diminua, que a insuficiência mitral diminua e, principalmente, que a embolia diminua; quem de nós já não operou paciente sem história de embolia prévia com ritmo sinusal e encontrou trombo no átrio esquerdo que não foi detectado, nem pelo eco nem pelo cateterismo; isto é um risco que temos que ter em mente. Eu gostaria de concluir dizendo que acredito que a valvoplastia mitral possa ter alguma atuação, pode provocar alguma abertura na valva, em alguns casos extremamente bem selecionados, sem cálcio, com boa mobilidade, sem estrutura subvalvar lesionada, mas jamais vai conseguir chegar naquilo que nós, cirurgiōes, conseguimos fazer com o bisturi. Com relação ao aórtico, acredito que ela seja paliativa e só está restrita a casos de riscos extremamente grandes. Muito obrigado. 